Research Article

\title{
Strength Recovery Model of Clay during Thixotropy
}

\author{
Bin Tang $\mathbb{D},{ }^{1}$ Biaohe Zhou $\mathbb{D},{ }^{2}$ Liang Xie $\mathbb{D},{ }^{2,3}$ Jianfeng Yin $\mathbb{D},{ }^{4}$ Shengnan Zhao $\mathbb{D},{ }^{2}$ \\ and Zhibing Wang iD $^{2}$ \\ ${ }^{1}$ Guangxi Key Laboratory of Geotechnical Mechanics and Engineering, Guilin University of Technology, Guilin 541004, China \\ ${ }^{2}$ Institute of Civil and Architectural Engineering, Guilin University of Technology, Guilin 541004, China \\ ${ }^{3}$ Geotechnical Engineering Company, Wuhan Surveying-Geotechnical Research Institute Co., Ltd., MCC Group, Wuhan 430080, \\ China \\ ${ }^{4}$ Hunan Nonferrous Institute of Engineering Prospecting Co., Ltd. Changsha, Hunan 410129, China
}

Correspondence should be addressed to Bin Tang; tangbin@glut.edu.cn

Received 30 August 2020; Revised 24 December 2020; Accepted 23 January 2021; Published 3 February 2021

Academic Editor: Wen-Chieh Cheng

Copyright ( $\odot 2021$ Bin Tang et al. This is an open access article distributed under the Creative Commons Attribution License, which permits unrestricted use, distribution, and reproduction in any medium, provided the original work is properly cited.

\begin{abstract}
Thixotropy is a hot topic in the field of rheology of dispersed systems. Many researchers have proposed different models and hypotheses to explain the thixotropy of clay. In this paper, the strength recovery model of Zhanjiang Formation clay in the process of thixotropy is studied. Firstly, through unconfined compressive strength test, the influence of soil sensitivity, moisture content, and density on the strength growth of remolded soil was studied. The results show great influence of sensitivity, moisture content, and density on the thixotropic strength of the Zhanjiang Formation clay: the higher the sensitivity and the density, the stronger the thixotropy of soil; the higher the moisture content, the weaker the thixotropy of soil. Based on the test results, a strength recovery model of Zhanjiang Formation clay in the process of thixotropy was established. The model was verified by the validation test data and the data obtained from the existing literature. The results suggest that the model prediction is in good agreement with the verification test data and data from existing literature, which proves the confidence of the model in predicting the degree of strength recovery in the process of thixotropy of Zhanjiang Formation clay. The model provides basis for stability calculation of surrounding soil after construction disturbance of underground structures in this stratum.
\end{abstract}

\section{Introduction}

With the rapid development of urban construction in China, there are more and more underground structures that exploit and utilize underground space. During the construction of underground structures, the surrounding soil is disturbed and its strength reduced [1]. After completion of construction, the strength of soil will gradually recover due to thixotropy. Thixotropy is one of the complex rheological properties. The thixotropy of soil refers to the phenomenon that the structural strength of soil decreases sharply or even flows under the action of external forces, and the structure and strength gradually recover with the lapse of time after the external force stops [2]. In 1949, Boswell [3] made a thixotropic study on a large number of sedimentary aggregates and found that all materials except clean sand showed thixotropic characteristics. Díaz-Rodríguez and
Santamarina [4], Xiuli et al. [5], and Li et al. [6], respectively, studied the thixotropy of Mexican soil, Yellow River Delta silt, and Cuihu wetland soft soil. These results show that the influence of thixotropy can increase the strength of remolded soil to $100 \%$ or even higher. The study of thixotropy is of great guiding significance to deeply understand the mechanical mechanism of soil, solve the problem of engineering foundation stability, and prevent geological disasters. Some researchers have studied this from different aspects.

In terms of influencing factors of thixotropy, the moisture content of soil has an important influence on the thixotropy of soil [7-11]. Mitchell [12] pointed out that, compared with chemical factors, the moisture content of soil has an important influence on changing the intergranular force, then affecting the thixotropy of soil. Wang et al. [13] studied the thixotropy of dredged silt from Taihu Lake and 
Baima Lake with different moisture content and found that the smaller the moisture content, the greater the thixotropy. Thixotropic agents can change the thixotropy of materials to a great extent, and the thixotropy is related to the density of materials [14-16]. Quanji et al. [17] found that adding a small amount of nanoclay can significantly promote the reflocculation or structural reconstruction of particles and effectively improve the thixotropy of cement paste. Qian and De Schutter [18] used nanoclay and moisture reducing agent to change the thixotropy of cement paste at the same time, and these two additives greatly accelerate the microparticle agglomeration of cement paste. Appellants' researches on the influencing factors of thixotropy are mostly qualitative and lack quantitative description.

In terms of thixotropy mechanism, thixotropy is the result of the interaction between microscopic particles [19-22]. Li et al. [23] analyzed the change law of interparticle force and particle network structure with measurement time, measurement rate in paste yield process in mesolevel, and explained the thixotropy mechanism of whole tailings paste. Zhang et al. [24] used scanning electron microscope and mercury intrusion experiment to study the change law of microstructure and pores with time after clay remodeling in Zhanjiang Formation and attributed the strength increase to the adaptive adjustment of microstructure caused by the change of force field. Huo et al. [25] think that clay is an energy dissipation system. Upon shearing, one part of the energy input from the outside makes the particles slightly adjusted, rubbed, and then dissipated, while the other part is transferred to heat energy, which intensifies the thermal movement of particles. After curing for a period of time, the energy dissipates, and the particles converge again until a new balance is reached. These researchers have discussed the thixotropy mechanism from the aspects of microstructure, self-adaptive adjustment of microstructure, and energy dissipation, but the understanding of the mechanism of soil thixotropy still stays in the stage of incomplete qualitative explanation, lacking reliable test data support, and it is difficult to explain the nature of the occurrence and development of soil thixotropy in the root.

In terms of constitutive models, many researchers have proposed empirical models or semiempirical and semitheoretical constitutive models to describe the thixotropy of materials based on experiments or existing constitutive models of materials [26-33]. Mendes [34] put forward a constitutive model of structural fluid, which can well predict the thixotropy, viscoelasticity, and yield behavior of materials. Wei et al. [35] extended the previous pure scalar thixotropic "multilambda" model and combined it with the isotropic motion hardening (IKH) model, which reflected well the complex transient rheological behavior of the thixotropic viscoelastic plastic (TEVP) fluid. These models are more or less contradictory between the number of model parameters and the calculation accuracy, which makes it difficult to obtain general analytical solutions and accurate numerical solutions. Moreover, most of these models are proposed for some specific fluids, and it is difficult to apply them to engineering practice.

The above work has promoted the research progress of thixotropy of soil, but there are still some drawbacks in previous studies. First of all, there are a great many of the complex factors affecting thixotropy, and the current research has not studied the influence degree of these factors from a quantitative point of view. In addition, the existence of soil thixotropy has a great influence on the engineering practice [36-39]. For example, the construction processes such as pipe jacking and pile sinking will disturb the surrounding soil and reduce its strength. After completion of construction, the strength of the soil will gradually recover, showing timeliness [40-42]. The clay of Zhanjiang Formation features strong constitutive property [43], high plasticity [44], micropermeability [45], strong acidity produced by oxidation hydrolysis [46], spatial distribution difference [47], creep property [48], thixotropy [24], etc., and it is an extremely abnormal soil with special properties, resulting in its rare engineering characteristics. But the problems about the strength recovery law of structural clay in Zhanjiang Formation during thixotropy are still unclear, and a model which can accurately reflect the soil thixotropic strength recovery has not yet been established to guide the engineering practice. To find the thixotropic recovery model of clay strength, this paper studies the growth law of soil strength with curing time based on the unconfined compressive strength test of remolded soil of Zhanjiang Formation clay, discusses the influence of soil sensitivity, moisture content, and density on thixotropy, and puts forward a model to predict the strength growth of remolded soil during thixotropy. The parameters of the model are few and easy to obtain, which simplifies the previous model calculation and is convenient for engineering applications.

\section{Basic Physical Property Tests}

Through existing regional geological data and engineering geological surveys, typical strata are selected for investigation, drilling, and sampling. Three groups of undisturbed soil samples 1, 2, and 3 of Zhanjiang Formation clay were taken from Baosteel Zhanjiang Iron and Steel Base in Donghai Island, Zhanjiang City, Guangdong Province, China. The depth for soil sampling for sample groups 1, 2, and 3 is $33.25-34.05 \mathrm{~m}, 53.25-54.05 \mathrm{~m}$, and $65.25-66.05 \mathrm{~m}$, respectively. Sampling was carried out by using a stainless steel open thin-walled sampler with an inner diameter of $100 \mathrm{~mm}$, a wall thickness of $2 \mathrm{~mm}$, a cutting edge angle of $60^{\circ}$, and a length of $300 \mathrm{~mm}$. The upper end of the sampler was connected with a drill stem by screws and was provided with an exhaust (drain) hole and a spherical valve, to release air and water pressure during sampling, prevent water from reentering, and maintain a vacuum above the soil sample during lifting. The drying method, ring knife method, pycnometer method, and liquid-plastic limit combined method were used to test the basic physical properties such 
as natural moisture content, natural density, specific gravity, liquid limit, and plastic limit of the Zhanjiang Formation clay. For the test methods, refer to the relevant provisions of Articles 5.2, 6.2, and 7.2 of Standard for Geotechnical Test Methods (GB/T50123-2019), and the test results are shown in Table 1.

As shown in Table 1, the physical properties of structural clay in Zhanjiang Formation are inferior, with the characteristics of high water content and high plasticity.

\section{Influence of Sensitivity on Thixotropy}

Thixotropic property is caused by the restoration of soil structure with the lapse of standing time after the internal structure of the soil is destroyed. To study the influence of soil sensitivity $S_{t}$ on strength recovery, three groups of undisturbed soil samples 1, 2, and 3 with different sensitivity were remolded and the internal structure was destroyed to obtain remolded samples. The remoulding pattern is a homogeneous soil simulating the shape of undisturbed soil, which is obtained by drying and crushing the undisturbed soil, and then remoulding it according to the density and moisture content of the undisturbed soil. For the sample preparation method, refer to the relevant provisions of Articles 4.3.1 and 4.4.2 of Standard for Geotechnical Test Methods (GB/T50123-2019). Wrap the sample in preservative film, place it in PVC tubes, put on the lids, and seal with wax; store it in an airtight moisturizing jar for curing and control the room temperature at $25 \pm 2^{\circ} \mathrm{C}$. As shown in the researches that the soil strength recovery is fast at the initial stage and slow at the later stage $[4,5]$, we set the curing times at $0 \mathrm{~d}, 1 \mathrm{~d}, 7 \mathrm{~d}, 30 \mathrm{~d}$, and $60 \mathrm{~d}$. Unconfined compressive strength tests were carried out on three groups of Zhanjiang Formation clay with different sensitivity at different curing times, and the unconfined compressive strength values of undisturbed soil and remolded soil samples of different curing times were obtained. For the unconfined compressive strength test method, refer to the relevant provisions of Article 20 of Standard for Geotechnical Test Methods (GB/T 50123-2019), and the test results are shown in Table 2.

Table 2 suggests that the structural clay of Zhanjiang Formation has high strength, but the strength decreases greatly after remolding. With lapse of curing time, the strength increases obviously, and it has strong constitutive property and thixotropy. The structural clay of Zhanjiang Formation has inferior physical properties and superior mechanical properties, which makes rare engineering characteristics for the clay in Zhanjiang Formation.

To study the strength recovery law of Zhanjiang Formation clay during thixotropy, the relation between the unconfined compressive strength of remolded soil samples and the logarithm of curing time $q_{u}^{\prime}(t)-\log t$ was established, whereaslog $t$ is meaningless at $0 \mathrm{~d}$, and Table 2 shows that the values of $q_{u}^{\prime}(0)$ and $q_{u}^{\prime}(1)$ of the three groups of soil samples have little change and the error between them can be ignored. Therefore, the data with curing times of $1 \mathrm{~d}, 7 \mathrm{~d}$, $30 \mathrm{~d}$, and $60 \mathrm{~d}$ in Table 2 are selected to fit the curve of the relation between unconfined compressive strength of remolded soil samples and logarithm of curing time $q_{u}^{\prime}(t)-\log t$, and the results are shown in Figure 1 .

As can be seen from Figure $1, q_{u}^{\prime}(t)$ grows with $\log t$. The reason the strength of soil increases with the increase of curing time is the remolding input energy to the soil, part of which destroys the internal structure of the soil, and the other part of which is converted into heat energy, which intensifies the thermal movement of particles, and the particles are separated from each other, thus reducing the acting force between particles. After curing for a period of time, the energy dissipates, and the particles converge again until a new balance is reached, and the strength increases accordingly [25]. And there is a linear relation between $q_{u}^{\prime}(t)$ and $\log t$ :

$$
q_{u}^{\prime}(t)=A \log t+B,
$$

where $B$ is the intercept of the straight line $q_{u}^{\prime}(t)-\log t$, namely, $B=q_{u}^{\prime}(1)$, in $k P a$. Because $q_{u}^{\prime}(1) \approx q_{u}^{\prime}(0)$ in Table 2, we can approximately assume that

$$
B=q_{u}^{\prime}(1)=q_{u}^{\prime}(0)=\frac{q_{u}}{S_{t}} .
$$

$A$ is the slope of the straight line $q_{u}^{\prime}(t)-\log t$, in $\mathrm{kPa}$, which is related to the rate of strength recovery in the thixotropic process. Let $A=q_{u} a$, where $q_{u}$ is the unconfined compressive strength of undisturbed soil, in $\mathrm{kPa} . a$ is the coefficient related to the slope of a straight line $q_{u}^{\prime}(t)-\log t$, dimensionless. When $t=0$, it is true that

$$
A=q_{u} a=q_{u}^{\prime}(0) S_{t} a .
$$

The sizes of $A$ and $a$ reflect the thixotropy intensity degree of soil. The greater the $A$ and $a$, the stronger the thixotropy, whereas the weaker the thixotropy. According to the ratio of $q_{u}$ and $q_{u}^{\prime}(0)$ in Table 2 , the sensitivity $S_{t}$ of the three groups of samples is $4.07,5.53$, and 4.39 , respectively. It can be seen from Figure 1 that the greater the sensitivity is, the greater the A and the stronger the thixotropy of the soil is, which is consistent with the hypothetical results of (3).

To determine the coefficient $a$, the next section will discuss the influence of the basic physical properties of soil on the coefficient $a$.

\section{Influence of Moisture Content on Thixotropy}

Taking another group of Zhanjiang Formation clay from the field to study the influence of moisture content on thixotropy, the sampling method is the same as that in Section 2. The undisturbed soil has an unconfined compressive strength of $q_{u}=138.28 \mathrm{kPa}$, a moisture content of $45 \%$, and a density of $1.71 \mathrm{~g} / \mathrm{cm}^{3}$. The undisturbed soil was remolded to prepare remolded soil samples with the same density $\left(1.71 \mathrm{~g} / \mathrm{cm}^{3}\right)$ but different moisture content $(40 \%, 45 \%,+$ and $50 \%)$. The sample preparation method was the same as in Section 3. After curing the remolded soil samples for $1 \mathrm{~d}, 7 \mathrm{~d}$, $30 \mathrm{~d}$, and $60 \mathrm{~d}$, the unconfined compressive strength was measured, respectively, and the test method was the same as in Section 3. The test results are shown in Table 3. Establish the $q_{u}^{\prime}(t)-\log t$ relation curves of remolded soil samples 
TABLE 1: Test results of physical properties of Zhanjiang Formation clay.

\begin{tabular}{lccccc}
\hline Group & Moisture content $\omega(\%)$ & Natural density $\rho\left(\mathrm{g} / \mathrm{cm}^{3}\right)$ & Specific gravity $G_{s}$ & Liquid limit $w_{L}(\%)$ & Plastic limit $w_{p}(\%)$ \\
\hline 1 & 48.79 & 1.75 & 2.67 & 63.06 & 32.70 \\
2 & 38.01 & 1.76 & 2.71 & 52.10 & 31.23 \\
3 & 46.59 & 1.77 & 2.68 & 58.30 & 32.40 \\
\hline
\end{tabular}

TABLE 2: Unconfined compressive strength test results of samples with different sensitivity at different curing times.

\begin{tabular}{|c|c|c|c|c|c|c|}
\hline Group & $\begin{array}{l}\text { Undisturbed soil } \\
\text { sample } q_{u}(\mathrm{kPa})\end{array}$ & $\begin{array}{c}\text { Remolded soil } \\
\text { sample curing for } \\
0 \mathrm{~d} \\
q_{u}^{\prime}(0)(\mathrm{kPa})\end{array}$ & $\begin{array}{c}\text { Remolded soil } \\
\text { sample curing for } \\
1 \mathrm{~d} \\
q_{u}^{\prime}(1)(\mathrm{kPa})\end{array}$ & $\begin{array}{c}\text { Remolded soil } \\
\text { sample curing for } \\
7 \mathrm{~d} \\
q_{u}^{\prime}(7)(\mathrm{kPa})\end{array}$ & $\begin{array}{l}\text { Remolded soil } \\
\text { sample curing for } \\
30 \mathrm{~d} \\
q_{u}^{\prime}(30)(\mathrm{kPa})\end{array}$ & $\begin{array}{c}\text { Remolded soil } \\
\text { sample curing for } \\
60 \mathrm{~d} \\
q_{u}^{\prime}(60)(\mathrm{kPa})\end{array}$ \\
\hline 1 & 122.88 & 30.19 & 30.48 & 36.12 & 37.28 & 40.05 \\
\hline 2 & 183.65 & 33.21 & 33.56 & 41.24 & 54.37 & 56.42 \\
\hline 3 & 154.91 & 35.26 & 35.71 & 38.65 & 47.02 & 49.32 \\
\hline
\end{tabular}

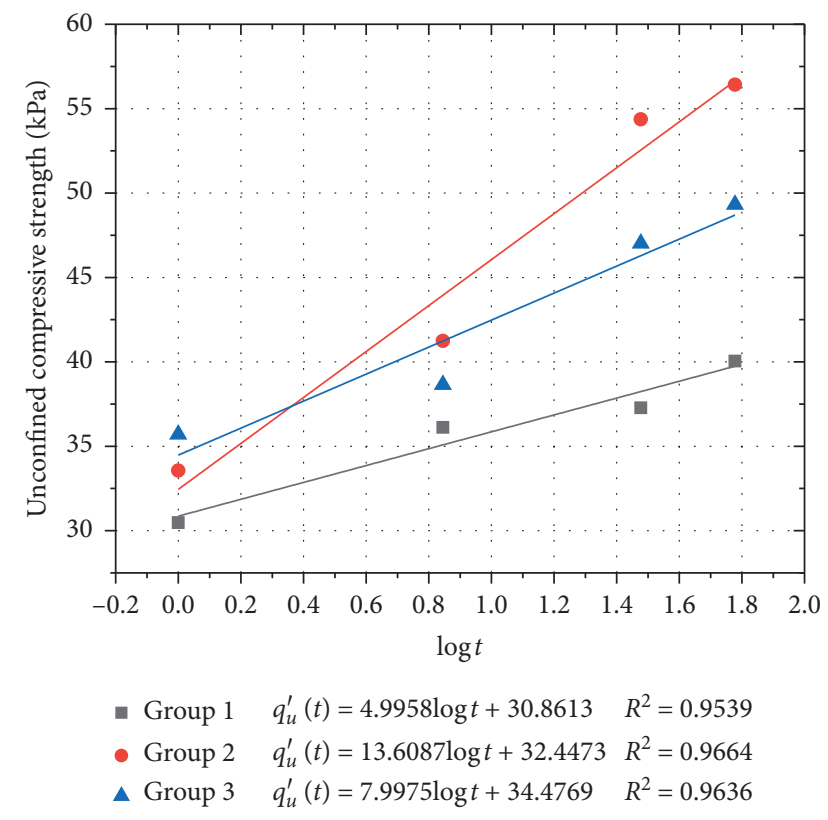

FIGURE 1: The $q_{u}^{\prime}(t)-\log t$ relation curve of samples with different sensitivity.

with different moisture content according to Table 3, as shown in Figure 2.

It can be seen from Figure 2 that the slope $A$ of the straight line $q_{u}^{\prime}(t)-\log t$ decreases with the increase of moisture content, indicating that the thixotropy of Zhanjiang Formation clay decreases with the increase of moisture content [13]. The reason is that the original cementation between particles is destroyed by remodeling. As a solvent, moisture will dissolve some cementation substances, and the concentration in samples with low moisture content is higher than that in samples with high moisture content. Therefore, after curing, the connection between particles of samples with lower moisture content is more obvious than that of samples with higher moisture content. It can be seen from formula (3) that, $A=q_{u} a$, the value of $a$ can be calculated by formula $a=A / q_{u}$ according to Figure 2, and $q_{u}=138.28 \mathrm{kPa}$, and the $a-w$ relation can be fitted linearly, as shown in Figure 3.

It can be seen from Figure 3 that $a$ decreases with the increase of $w$ and there is a linear relation between them:

$$
a=\alpha w+\beta
$$

where $\alpha$ is the slope of the $a-w$ relation curve, dimensionless; $\beta$ is the intercept of the $a-w$ relation curve, dimensionless; the moisture content $w$ is in decimal form.

\section{Influence of Density on Thixotropy}

Taking a group of Zhanjiang Formation clay from the field to study the influence of density on thixotropy, the sampling method is the same as that in Section 2. The undisturbed soil has an unconfined compressive strength of $q_{u}=154.91 \mathrm{kPa}$, a moisture content of $46.59 \%$, and a density of $1.85 \mathrm{~g} / \mathrm{cm}^{3}$. The unaltered soil was remolded to prepare remolded soil samples with the same moisture content $(46.59 \%)$ but different densities $\left(1.89 \mathrm{~g} / \mathrm{cm}, 1.85 \mathrm{~g} / \mathrm{cm}^{3}\right.$, and $\left.1.77 \mathrm{~g} / \mathrm{cm}^{3}\right)$. The sample preparation method was the same as in Section 3. After curing the remolded soil samples for $1 \mathrm{~d}, 7 \mathrm{~d}, 30 \mathrm{~d}$, and $60 \mathrm{~d}$, the unconfined compressive strength was measured, respectively, and the test method was the same as in Section 3. The test results are shown in Table 4. Establish the $q_{u}^{\prime}(t)-$ $\log t$ relation curves of remolded soil samples with different densities according to Table 4, as shown in Figure 4.

It can be seen from Figure 4 that the slope $A$ of the straight line $q_{u}^{\prime}(t)-\log t$ increases with the increase of density $\rho$, indicating that the thixotropy of Zhanjiang Formation clay increases with the increase of density. The smaller the pore ratio of soil, the greater the thixotropy of soil [11], and the smaller the pore ratio of soil, the higher its density, the smaller the spacing between soil particles, and the larger the contact area. After curing, the connection between particles is more obvious than that of less dense soil, so the thixotropy of dense soil is stronger. Therefore, the thixotropy of soil with high density is stronger. It can be seen from formula (3) that, $A=q_{u} a$, the values of $a$ can be calculated by $a=A / q_{u}$ according to Figure 4 and 
TABLE 3: Unconfined compressive strength of remolded samples with different moisture contents at different curing times.

\begin{tabular}{lcccc}
\hline $\begin{array}{l}\text { Moisture content } \\
(\%)\end{array}$ & $\begin{array}{c}\text { Remolded soil sample } \\
\text { curing for } 1 \mathrm{~d} \\
q_{u}^{\prime}(1)(\mathrm{kPa})\end{array}$ & $\begin{array}{c}\text { Remolded soil sample } \\
\text { curing for } 7 \mathrm{~d} \\
q_{u}^{\prime}(7)(\mathrm{kPa})\end{array}$ & $\begin{array}{c}\text { Remolded soil sample curing } \\
\text { for } 30 \mathrm{~d} \\
q_{u}^{\prime}(30)(\mathrm{kPa})\end{array}$ & $\begin{array}{c}\text { Remolded soil sample curing } \\
\text { for } 60 \mathrm{~d} \\
q_{u}^{\prime}(60)(\mathrm{kPa})\end{array}$ \\
\hline 40 & 28.51 & 33.22 & 40.68 & 41.85 \\
45 & 18.17 & 21.34 & 26.67 & 30.17 \\
50 & 8.54 & 10.64 & 13.17 & 15.75 \\
\hline
\end{tabular}

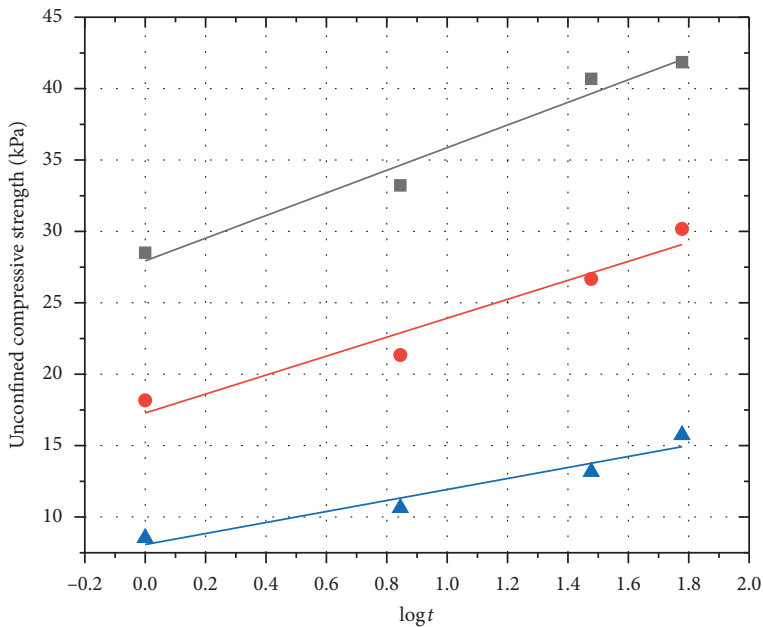

- Moisture content of $40 \% \quad-q_{u}^{\prime}(t)=7.9256 \log t+27.9405 \quad R^{2}=0.9714$

- Moisture content of $45 \% \quad-q_{u}^{\prime}(t)=6.6365 \log t+17.2845 \quad R^{2}=0.9473$

A Moisture content of $50 \% \quad q_{u}^{\prime}(t)=3.8522 \log t+8.0761 \quad R^{2}=0.9409$

Figure 2: Relation curve $q_{u}^{\prime}(t)-\log t$ of samples with different moisture content.

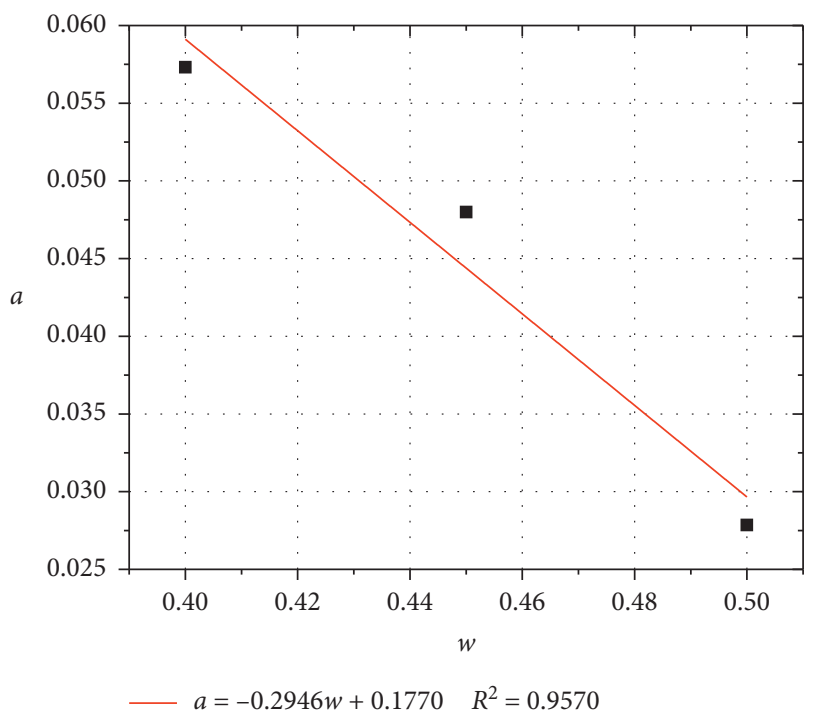

FIgURE 3: Relation curve $a-w$.

$q_{u}=154.91 \mathrm{kPa}$, and the $a-\rho$ relation can be fitted linearly, as shown in Figure 5.

As can be seen from Figure 5, $a$ increases with the increase of $\rho$, demonstrating a linear relation between them:

$$
a=\gamma \rho+\eta,
$$

where $\gamma$ is the slope of the $a-\rho$ relation curve, dimensionless; $\eta$ is the intercept of the $a-\rho$ relation curve, dimensionless; for $\rho$, the value with dimension removed is taken.

Figures 3 and 4 show a linear relation between $a$ and moisture content $w$, density $\rho$ within a certain range, and the corresponding values of $w, \rho$, and $a$ in Figures 3 and 4 shown in Table 5.

On the ground that both moisture content $w$ and density $\rho$ have a linear relation with $a$ within a certain range, we can use a binary linear regression method to carry out regression analysis and determine their quantitative relation, assuming that the quantitative relation among them is

$$
a=k_{0}+k_{1} w+k_{2} \rho,
$$

where $k_{0}, k_{1}$, and $k_{2}$ are regression parameters, dimensionless. and 7.

The results of regression analysis are shown in Tables 6

According to Table 6 , the linear regression coefficient multiple $R=0.8995$, indicating that $w, \rho$, and $a$ are correlated. The value of significance $F$ is 0.0834 , showing a significant regression effect. As shown in Table 7, the values of $k_{0}, k_{1}$, and $k_{2}$ in $(6)$ are $-0.1777,-0.3291$, and 0.2143 , respectively; then,

$$
a=-0.1777-0.3291 w+0.2143 \rho
$$

\section{Thixotropic Strength Recovery Model}

In terms of prediction model, Zhang Xianwei studied the strength growth law of different curing times after clay remolding through unconfined compressive strength test and penetration test and put forward the empirical formula of strength recovery as a power function form [24].

$$
q_{u}^{\prime}(t)=C t^{D}
$$

Because the parameter meaning of the power function is not clear, the logarithm of the power function is used to make the parameter meaning clear. In this paper, the empirical formula in logarithmic form (1) is obtained by data fitting. According to the above analysis, sensitivity, moisture content, and density have obvious influences on thixotropic recovery. Substituting (2), (3), and (6) into (1), the thixotropic strength recovery model of Zhanjiang Formation clay can be obtained: 
TABLE 4: Unconfined compressive strength of remolded samples with different densities at different curing times.

\begin{tabular}{lcccc}
\hline $\begin{array}{l}\text { Density } \\
\left(\mathrm{g} / \mathrm{m}^{3}\right)\end{array}$ & $\begin{array}{c}\text { Remolded soil sample curing } \\
\text { for } 1 \mathrm{~d} \\
q_{u}^{\prime}(1)(\mathrm{kPa})\end{array}$ & $\begin{array}{c}\text { Remolded soil sample curing } \\
\text { for } 7 \mathrm{~d} \\
q_{u}^{\prime}(7)(\mathrm{kPa})\end{array}$ & $\begin{array}{c}\text { Remolded soil sample curing } \\
\text { for } 30 \mathrm{~d}\end{array}$ & $\begin{array}{c}\text { Remolded soil sample curing } \\
\text { for } 60 \mathrm{~d} \\
q_{u}^{\prime}(30)(\mathrm{kPa})\end{array}$ \\
\hline 1.89 & 28.94 & 35.69 & 43.13 & 53.66 \\
1.83 & 26.17 & 30.56 & 36.91 & 41.59 \\
1.77 & 26.15 & 28.79 & 32.45 & 36.52 \\
\hline
\end{tabular}

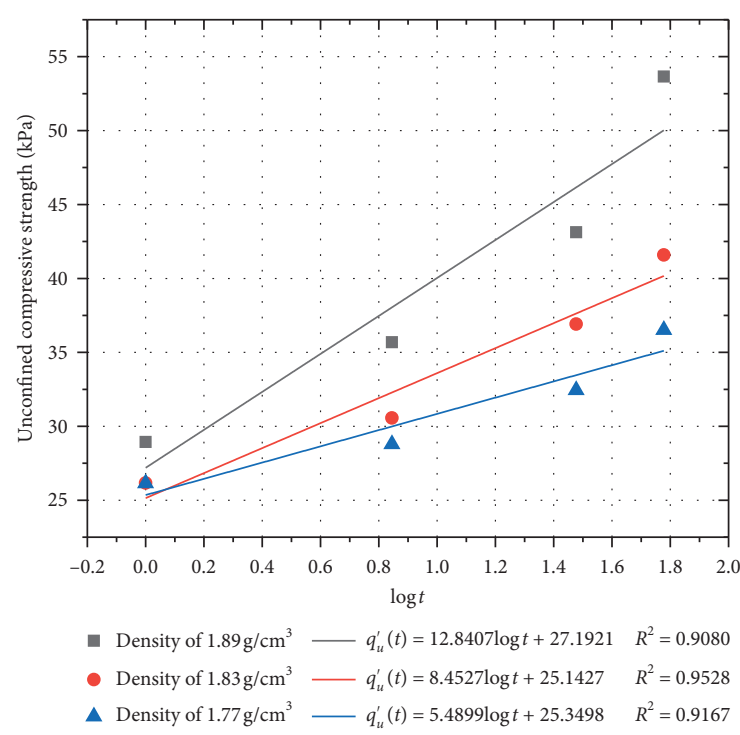

Figure 4: Relation curve $q_{u}^{\prime}(t)-\log t$ of samples with different densities.

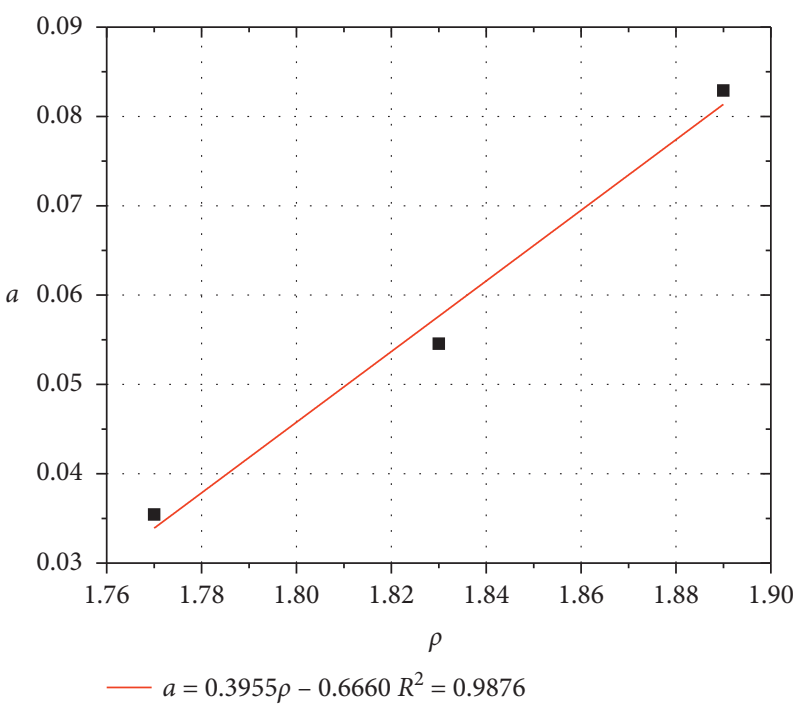

FIgURE 5: Relation curve $a-\rho$.

$$
q_{u}^{\prime}(t)=q_{u}^{\prime}(0) S_{t}\left(k_{0}+k_{1} w+k_{2} \rho\right) \log t+\frac{q_{u}}{S_{t}}
$$

where $q_{u}^{\prime}(t)$ is the unconfined compressive strength corresponding to the curing time $t$, in $\mathrm{kPa} ; q_{u}^{\prime}(0)$ is the unconfined
TABLE 5: The test values of $w \rho$, and $a$.

\begin{tabular}{lcccccc}
\hline Indicators & \multicolumn{7}{c}{ Values } \\
\hline$w$ & 0.4 & 0.45 & 0.4659 & 0.4659 & 0.4659 & 0.5 \\
$\rho$ & 1.71 & 1.71 & 1.77 & 1.83 & 1.89 & 1.71 \\
$a$ & 0.0573 & 0.0480 & 0.0354 & 0.0546 & 0.0829 & 0.0279 \\
\hline
\end{tabular}

TABLE 6: Regression statistics.

\begin{tabular}{lc}
\hline Regression parameters & Values \\
\hline Multiple $R$ & 0.8995 \\
$R$ square & 0.8091 \\
Adjusted $R$ square & 0.6818 \\
Standard error & 0.0109 \\
Significance $F$ & 0.0834 \\
Observed value & 6 \\
\hline
\end{tabular}

TABLE 7: Regression parameters.

\begin{tabular}{lc}
\hline Coefficients & Values \\
\hline Intercept & -0.1777 \\
$w$ variable 1 & -0.3291 \\
$\rho$ variable 2 & 0.2143 \\
\hline
\end{tabular}

compressive strength corresponding to the curing time at $0 \mathrm{~d}$, in $\mathrm{kPa} ; q_{u}$ is the unconfined compressive strength of undisturbed soil, in $\mathrm{kPa} ; w$ takes its decimal form; $\rho$ takes the value with dimension removed; $k_{0}, k_{1}$, and $k_{2}$ are model parameters, dimensionless, determined by referring to the determination method in Section 4.

Substituting the values of $k_{0}, k_{1}$, and $k_{2}$ into (9), we get

$$
q_{u}^{\prime}(t)=q_{u}^{\prime}(0) S_{t}(-0.1777-0.3291 w+0.2143 \rho) \log t+\frac{q_{u}}{S_{t}} .
$$

It can be seen from formula (10) that the model considers the influence of moisture content, density, and sensitivity on thixotropy, where the coefficient of moisture content is negative, and the greater the moisture content, the smaller the soil strength growth, and vice versa. The coefficient of sensitivity and density is positive, and the greater the sensitivity and density, the more obvious the soil strength growth. Deriving $t$ from (9), we get

$$
\frac{\mathrm{d} q_{u}^{\prime}(t)}{\mathrm{d} t}=\frac{q_{u}^{\prime}(0) S_{t}\left(k_{0}+k_{1} w+k_{2} \rho\right)}{t \ln 10} .
$$

By substituting the test data of groups 1, 2, and 3 into formula (11) according to Table 1, the curves of thixotropic 


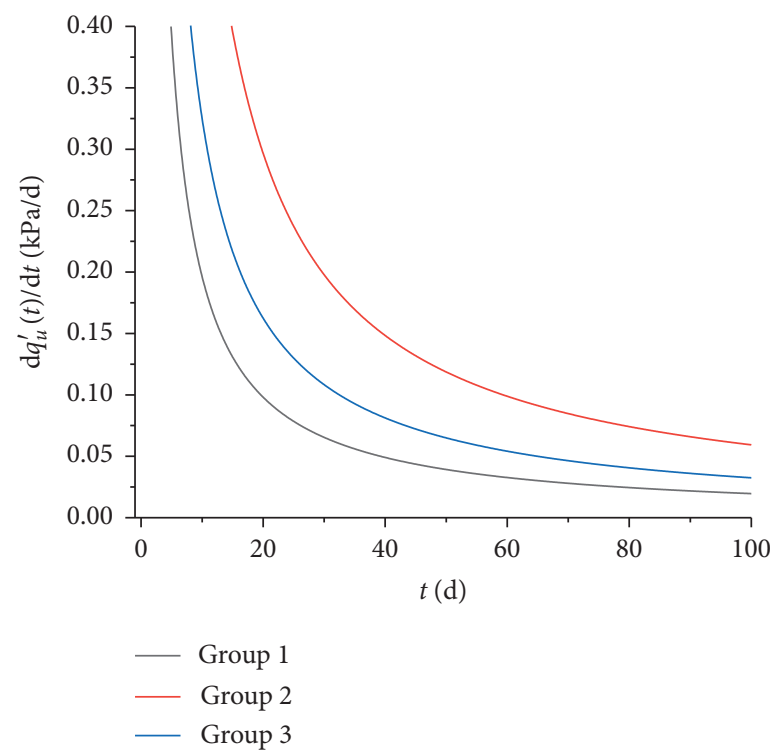

FIgure 6: The relation curve of thixotropic strength recovery rate and curing time.

recovery rates of the three groups soil samples changing with time can be obtained, as shown in Figure 6 .

It can be seen from Figure 6 that the thixotropic recovery rate of the three groups of soil samples decreases with the increase of curing time. Specifically, it decreases rapidly within 0 to 60 days and, after 60 days, tends to be stable and keeps stable at a smaller value, indicating that the thixotropic recovery is very slow after 60 days of curing time, and the strength of the soil cannot be restored to the strength of the original soil in a short time after the structure of the soil is destroyed.

\section{Model Verification}

To verify the rationality of the model, three different groups of undisturbed soil 4, 5, and 6 of Zhanjiang Formation clay were taken for verification test. The depth of soil sampling for specimens 4,5 , and 6 is $2.00-3.00 \mathrm{~m}, 6.00-9.00 \mathrm{~m}$, and $19.25-20.05 \mathrm{~m}$, respectively. The basic physical properties such as natural moisture content, natural density, and specific gravity of the soil samples taken for the verification test were measured. Sampling and testing methods are the same as those in Section 2, and the results are shown in Table 8 .

Unconfined compressive strength tests were carried out on undisturbed soil samples and remolded soil samples with different curing times $(0 \mathrm{~d}, 1 \mathrm{~d}, 5 \mathrm{~d}, 10 \mathrm{~d}, 15 \mathrm{~d}, 30 \mathrm{~d}$, and $60 \mathrm{~d}$ ) for the three groups 4, 5, and 6 of Zhanjiang Formation clay, and the unconfined compressive strength values of undisturbed soil and remolded soil samples with different curing times were obtained. The testing method is the same as that in Section 3, as shown in Table 9.
Using formula (10) to predict the intensity recovery of groups 4,5 , and 6 , substituting the initial conditions of soil groups 4, 5, and 6 into formula (10) according to Tables 8 and 9 , we get the strength recovery prediction curves for groups 4,5 , and 6 as follows:

$$
\begin{aligned}
& q_{u}^{\prime}(t)=0.1951 \log t+5.11, \\
& q_{u}^{\prime}(t)=4.8554 \log t+27.02, \\
& q_{u}^{\prime}(t)=10.6613 \log t+49.68 .
\end{aligned}
$$

The test data in Table 9 are compared with the prediction results of formulas (12)-(14), and the results are shown in Figure 7.

To further verify the rationality of the model, the test data of the literature [24] is quoted to verify the model, and the data of the literature [24] are shown in Tables 10 and 11.

Substituting the physical and mechanical indexes into formula (10) according to Tables 10 and 11, the strength recovery prediction curve is as follows:

$$
\begin{aligned}
& q_{u}^{\prime}(t)=2.65 \log t+25, \\
& q_{u}^{\prime}(t)=7.96 \log t+20.68, \\
& q_{u}^{\prime}(t)=51.31 \log t+94.15 .
\end{aligned}
$$

Comparing the test data in Table 11 with the prediction result of formulas (15)-(17), the result is shown in Figure 8.

It can be seen from Figures 7 and 8 that the test data are in good agreement with the predicted results of the model, and the theoretical curve calculated by this model can reflect 
TABLE 8: The test results of physical properties of Zhanjiang Formation clay.

\begin{tabular}{lccc}
\hline Group & Moisture content $\omega(\%)$ & Natural density $\rho\left(\mathrm{g} / \mathrm{cm}^{3}\right)$ & Specific gravity $G_{s}$ \\
\hline 4 & 55.38 & 1.71 & 2.67 \\
5 & 45.79 & 1.72 & 2.71 \\
6 & 42.26 & 1.71 & 2.72 \\
\hline
\end{tabular}

TABLE 9: Unconfined compressive strength test results of samples at different curing times.

\begin{tabular}{lcccccccc}
\hline Group & $q_{u}(\mathrm{kPa})$ & $q_{u}^{\prime}(0)(\mathrm{kPa})$ & $q_{u}^{\prime}(1)(\mathrm{kPa})$ & $q_{u}^{\prime}(5)(\mathrm{kPa})$ & $q_{u}^{\prime}(10)(\mathrm{kPa})$ & $q_{u}^{\prime}(15)(\mathrm{kPa})$ & $q_{u}^{\prime}(30)(\mathrm{kPa})$ & $q_{u}^{\prime}(60)(\mathrm{kPa})$ \\
\hline 4 & 30.02 & 5.11 & 5.11 & 5.35 & 5.41 & 5.54 & 5.60 & 5.73 \\
5 & 120.78 & 27.02 & 27.54 & 28.42 & 32.88 & 34.74 & 35.20 & 35.66 \\
6 & 214.62 & 49.68 & 50.62 & 53.46 & 58.79 & 62.64 & 67.38 \\
\hline
\end{tabular}

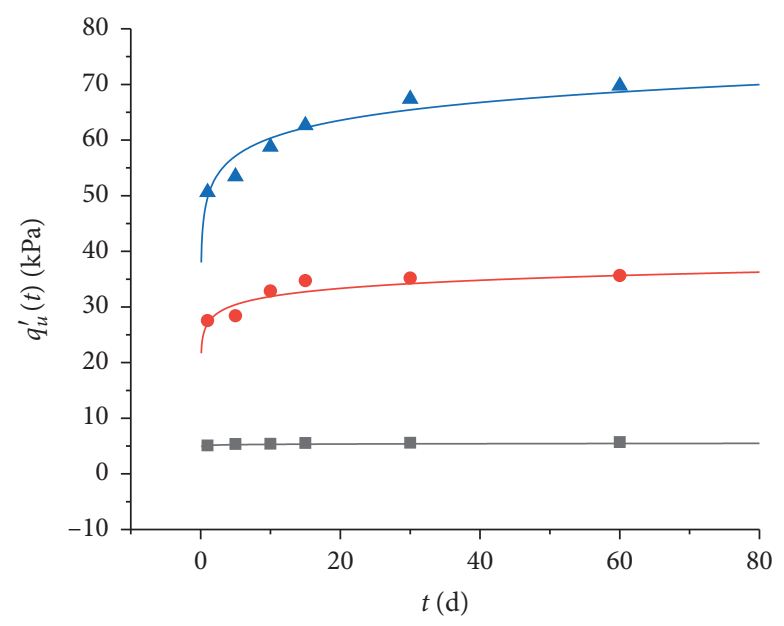

- Soil sample 4

- Soil sample 5

A Soil sample 6

Figure 7: Comparison of test data and model prediction.

TABLE 10: The physical and mechanical indexes of clay of the literature [24].

\begin{tabular}{lccc}
\hline Group & Moisture content $\omega(\%)$ & Natural density $\rho\left(\mathrm{g} / \mathrm{cm}^{3}\right)$ & Sensitivity $S_{t}$ \\
\hline 7 & 50.00 & 1.67 & 7 \\
8 & 40.13 & 1.70 & 7 \\
9 & 35.00 & 1.73 & 7 \\
\hline
\end{tabular}

TABLE 11: Strength at different curing times of clay of the literature [24].

\begin{tabular}{|c|c|c|c|c|c|c|}
\hline Group & $q_{u}^{\prime}(0)(\mathrm{kPa})$ & $q_{u}^{\prime}(5)(\mathrm{kPa})$ & $q_{u}^{\prime}(10)(\mathrm{kPa})$ & $q_{u}^{\prime}(15)(\mathrm{kPa})$ & $q_{u}^{\prime}(30)(\mathrm{kPa})$ & $q_{u}^{\prime}(60)(\mathrm{kPa})$ \\
\hline 7 & 25.00 & 27.17 & 28.46 & 29.31 & 31.02 & 33.14 \\
\hline 8 & 20.68 & 27.12 & 29.03 & 30.05 & 33.01 & 35.32 \\
\hline 9 & 94.15 & 129.52 & 143.25 & 156.37 & 168.90 & 187.26 \\
\hline
\end{tabular}




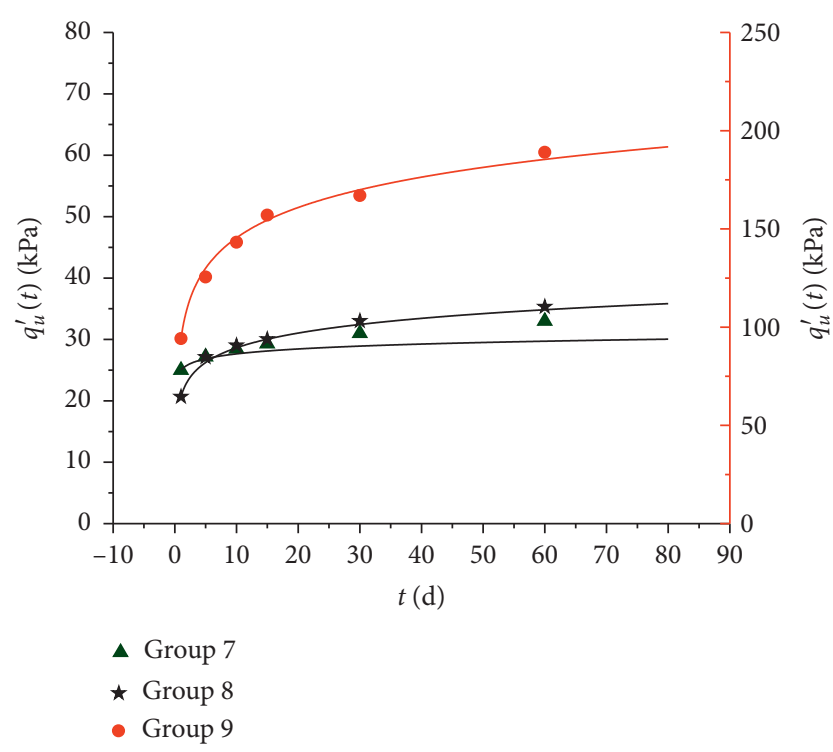

Figure 8: Comparison of the data of the literature [24] and model prediction.

the law of strength recovery of structural clay in Zhanjiang Formation during thixotropy.

\section{Conclusion}

In this paper, Zhanjiang Formation clay of undisturbed soil and remolded soil at different curing times is taken as research object. Through a series of unconfined compressive strength tests, the relation between thixotropic strength growth and curing time and the relation of sensitivity, moisture content, density of soil, and its thixotropy are studied, and the strength recovery model considering the influence of sensitivity, moisture content, and density on thixotropy is established.

(1) Curing for 60 days after remolding, the strength of Zhanjiang Formation clay increased by $30 \%$ of its initial strength, showing obvious thixotropy. The relation between the logarithm of curing time and strength is fitted, and the fitting parameters $R^{2}$ are all greater than 0.95 . The logarithmic form can reflect the law of strength growth.

(2) Sensitivity, moisture content, and density have great influence on the thixotropic strength of the Zhanjiang Formation clay, and the higher the sensitivity and density are, the stronger the thixotropy of soil is. The higher the moisture content is, the weaker the thixotropy of soil is.

(3) Based on the test results, considering the effects of sensitivity, moisture content, and density on thixotropy, a strength recovery model of remolded soil in Zhanjiang Formation was established: $q_{u}^{\prime}(t)=q_{u}^{\prime}(0) S_{t}\left(k_{0}+k_{1} w+k_{2} \rho\right) \log t+q_{u} / S_{t}$. The model could be used to predict the degree of strength recovery in the process of thixotropy of Zhanjiang Formation clay.
(4) The model is validated by the validation test data and the existing literature data, and the model prediction data is in good agreement with the validation test data and the existing literature data.

\section{Data Availability}

The experimental data used to support the findings of this study are provided in the article.

\section{Conflicts of Interest}

The authors declare that there are no conflicts of interest.

\section{Acknowledgments}

This work was supported by the National Natural Science Foundation of China (41867035), the Project of Guangxi Key Laboratory of Geotechnical Mechanics and Engineering (2016-A-01), Guangxi Key Laboratory of Geomechanics and Geotechnical Engineering of China (no. 13-KF-05), and Guangxi Natural Science Foundation under Grant no. 2017GXNSFAA198092. The authors gratefully acknowledge the financial support.

\section{References}

[1] W.-C. Cheng, L. Ge, N. Liu, J. Xu, and S. Horpibulsuk, "Recent massive incidents for subway construction in soft alluvial deposits of Taiwan: a review," Tunnelling and Underground Space Technology incorporating Trenchless Technology Research, vol. 96, 2020.

[2] J. C. Ruge, F. Molina-Gómez, and J. P. Rojas, "Thixotropic behaviour study of clayey soils from the lacustrine deposits of Bogotá high plateau," in Proceedings of the 5th International Meeting for Researchers in Materials and Plasma Technology (5th IMRMPT), vol. 1386, San José de Cúcuta, Colombia, May 2019.

[3] P. G. H. Boswell, "A preliminary examination of the thixotropy of some sedimentary rocks," Quarterly Journal of Geological Science, vol. 104, p. 499, 1949.

[4] J. A. Díaz-Rodríguez and J. C. Santamarina, "Thixotropy: the case of mexico city soils," in Proceedings of the XI Panamerican Conference on Soils Mechanics and Geotechnical Engineering, pp. 441-448, Curitiba, Brazil, 1999.

[5] F. Xiuli, S. Zhou, and L. Lin, "Study on thixotropy of silt in modern Yellow River delta and its application," Ocean University of China Acta Sinica, vol. 36, no. 6, pp. 1053-1056, 2004.

[6] L. Li, L. Chen, and S. Gao, "Experimental study on thixotropy of soft soil in Cuihu Wetland," Rock and Soil Mechanics, vol. 31, no. 3, pp. 765-768, 2010.

[7] S. Sochan and H. Tanaka, "Properties of very soft clays: a study of thixotropic hardening and behavior under low consolidation pressure," Soils and Foundations, vol. 52, no. 2, 2012.

[8] K. H. Andersen and S. Yang, "Thixotropy of marine clays," Geotechnical Testing Journal, vol. 39, no. 2, 2015.

[9] A. Rafat Shahriar, M. Zoynul Abedin, and R. Jadid, "Thixotropic aging and its effect on 1-D compression behavior of soft reconstituted clays," Applied Clay Science, vol. 153, 2018.

[10] A. Rafat Shahriar and R. Jadid, "An experimental investigation on the effect of thixotropic aging on primary and 
secondary compression of reconstituted dredged clays," Applied Clay Science, vol. 162, 2018.

[11] M. Zhang, J. Yin, and W. Wang, "Influence of physical and mechanical properties of structural clay of Zhanjiang formation on its thixotropy," Journal of Engineering Geology, pp. 1-9, 2020.

[12] J. K. Mitchell, "Fundamental aspects of thixotropy in soils," Journal of the Soil Mechanics and Foundations Division, vol. 86, no. 3, pp. 803-836, 1960.

[13] L. Wang, L. Cao, and Li Lei, "Study on thixotropic characteristics of dredged silt in Taihu Lake and Baima Lake," Journal of Engineering Geology, vol. 23, no. 3, pp. 548-553, 2015.

[14] Y. Wang, S. Xu, and G. Wang, "Experiment and characteristics of thixotropic cement slurry materials proportioning," Coal Mine Safety, vol. 50, no. 3, pp. 35-37, 2019.

[15] B. Liang, W. Ji, and Z. Qin, "Study on preparation and properties of highly thixotropic tailings filling materials," Nonmetallic Minerals, vol. 43, no. 3, pp. 50-52, 2020.

[16] Yu Liu, M. Li, and P. Yan, "Effect of mineral admixtures on rheological property and thixotropy of cementitious materials slurry," Journal of Silicate, vol. 47, no. 5, pp. 594-601, 2019.

[17] Z. Quanji, G. R. Lomboy, and K. Wang, "Influence of nanosized highly purified magnesium alumino silicate clay on thixotropic behavior of fresh cement pastes," Construction and Building Materials, vol. 69, 2014.

[18] Y. Qian and G. De Schutter, "Enhancing thixotropy of fresh cement pastes with nanoclay in presence of polycarboxylate ether superplasticizer (PCE)," Cement and Concrete Research, vol. 111, 2018.

[19] A. Jacobsson and P. Roland, "Thixotropic action in remoulded quick clay," Bulletin of the International Association of Engineering Geology, vol. 5, no. 1, 1972.

[20] C. Martin, P. Frédéric, P. Jean-Michel, M. Albert, L. Peter, and C. Bernard, "Dissociation of thixotropic clay gels," Physical Review. E, Statistical, Nonlinear, and Soft Matter Physics, vol. 66, no. 2, 2002.

[21] X. W. Zhang, L. W. Kong, A. W. Yang, and H. M. Sayem, "Thixotropic mechanism of clay: a microstructural investigation," Soils and Foundations, vol. 57, no. 1, 2017.

[22] G. Landrou, C. Brumaud, M. L. Plötze, W. Frank, and G. Habert, "A fresh look at dense clay paste: deflocculation and thixotropy mechanisms," Colloids and Surfaces A: Physicochemical and Engineering Aspects, vol. 539, 2018.

[23] C. Li, B. Yan, S. Wang, H. Hou, and G. Chen, "Yield stress variability behavior of full tailings paste under time-rate double factors," Chinese Journal of Engineering, vol. 42, no. 10, pp. 1308-1317, 2020.

[24] X. Zhang, L. Kong, and J. Li, "Microscopic mechanism of strength recovery during thixotropy of clay," Chinese Journal of Geotechnical Engineering, vol. 36, no. 8, pp. 1407-1411, 2014.

[25] H. Huo, L. Qi, and H. Lei, "Thinking and experimental study on thixotropy of Tianjin soft clay," Chinese Journal of Rock Mechanics and Engineering Newspaper, vol. 35, no. 3, pp. 631-637, 2016.

[26] K. Dullaert and J. Mewis, "A structural kinetics model for thixotropy," Journal of Non Newtonian Fluid Mechanics, vol. 139, no. 1-2, pp. 21-30, 2006.

[27] H. A. Barnes, "Thixotropy-a review," Journal of Non-newtonian Fluid Mechanics, vol. 70, no. 1-2, pp. 1-33, 1997.

[28] G. Q. Guo, "Some constitutive models of thixotropic fluids," Mechanics and Practice, vol. 2, no. 6, pp. 20-22, 2000.
[29] D. Konraad and M. Jan, "A structural kinetics model for thixotropy," Journal of Non-newtonian Fluid Mechanics, vol. 139, no. 1, pp. 21-30, 2006.

[30] Y. Xu, H. Xu, and N. Wu, "Numerical simulation of thixotropy of highly sensitive soft soil," in Proceedings of the First National Seminar on Geotechnical Constitutive Theory, pp. 240-245, Beijing, China, 2008.

[31] Y. Zhang, D. Gan, and X. Chen, "Shear thixotropy experiment of tailings cemented filling slurry and its thixotropy prediction model based on dimensional analysis," Chinese Journal of Nonferrous Metals, vol. 30, no. 4, pp. 951-959, 2020.

[32] Z. Wang, C. Lu, and Z. Xu, "The thixotropy of saturated sand under cyclic loading," Chinese Journal of Geotechnical Engineering, vol. 36, no. 10, pp. 1831-1837, 2014.

[33] J. Li, W. Wang, Y. Zhu, H. Xu, and X. Xie, "An elastic-viscoplastic model for time-dependent behavior of soft clay and its application on rheological consolidation," Mathematical Problems in Engineering, vol. 2014, Article ID 587412, 14 pages, 2014.

[34] P. R. D. Mendes, "Thixotropic elasto-viscoplastic model for structured fluids," Soft Matter, vol. 7, p. 2471, 2011.

[35] Y. Wei, M. J. Solomon, and R. G. Larson, "A multimode structural kinetics constitutive equation for the transient rheology of thixotropic elasto-viscoplastic fluids," Journal of Rheology, vol. 62, no. 1, pp. 321-342, 2018.

[36] G. B. Kul'Chitskii, "Thixotropy of soils of the Middle Ob region and its consideration when constructing pile foundations," Soil Mechanics and Foundation Engineering, vol. 12, no. 3, pp. 168-170, 1975.

[37] Y. Xu, C. Wang, and M. Huang, "Study on thixotropy of saturated soft soil in wet-sprayed pile construction," Chinese Journal of Geotechnical Engineering, vol. 35, no. 10, pp. 1784-1789, 2013.

[38] AJ. Lutenegger, "Aged undrained shear strength of remolded clays," in Proceedings of the 8th International Conference Offshore Site Investigation Geotechnics, no. 6, pp. 378-383, London, UK, September 2017.

[39] H. A. Al-Janabi and C. P. Aubeny, "Experimental measurement of thixotropy and sensitivity in gulf of Mexico clay," in Proceedings of the29th International Ocean and Polar Engineering Conference, pp. 16-21, Honolulu, HI, USA, June 2019.

[40] Li Lin, J. Li, D. Sun, and F. Rui, “Time-effect study on bearing capacity of static pressure pile on natural saturated clay foundation," Rock and Soil Mechanics, vol. 38, no. 9, pp. 2515-2522, 2017.

[41] W.-C. Cheng, J. C. Ni, A. Arulrajah, and H.-W. Huang, "A simple approach for characterising tunnel bore conditions based upon pipe-jacking data," Tunnelling and Underground Space Technology, vol. 71, pp. 494-504, 2018.

[42] W.-C. Cheng, L. Wang, Z.-F. Xue, J. C. Ni, M. M. Rahman, and A. Arulrajah, "Lubrication performance of pipejacking in soft alluvial deposits," Tunnelling and Underground Space Technology Incorporating Trenchless Technology Research, vol. 91, 2019.

[43] J.-H. Shen, R. Wang, and Y. Zheng, "Research on regional microstructure characteristics of structural clay of Zhanjiang formation," Rock and Soil Mechanics, vol. 34, no. 7, pp. 1931-1936, 2013.

[44] X. W. Zhang, L. W. Kong, A. G. Guo, and Y. F. Tuo, "Experiment study of pore distribution of strong structural clay under different consolidation pressures," Rock and Soil Mechanics, vol. 35, no. 10, pp. 2794-2800, 2014.

[45] X. W. Zhang, L. W. Kong, A. Guo, and Y. Tuo, "Evolution of microscopic pore of structured clay in compression process 
based on SEM and MIP test," Chinese Journal of Rock Mechanics and Engineering, vol. 31, no. 2, pp. 406-412, 2012.

[46] X.-W. Zhang, L. W. Kong, and C. Cheng, "Effects of hydrochemistry on structural strength of Zhanjiang formation clay," Chinese Journal of Geotechnical Engineering, vol. 39, no. 11, pp. 1967-1975, 2017.

[47] J.-H. Shen, R. Wang, and C. Q. Zhu, "Research on spatial distribution law of gray clays of Zhanjiang formation," Rock and Soil Mechanics, vol. 34, no. S1, pp. 331-336, 2013.

[48] L. W. Zhong, L.-J. He, and X.-W. Zhang, "Creep model of Zhanjiang clay and plastic components with variable parameters," Rock and Soil Mechanics, vol. 33, no. 8, pp. 22412246, 2012. 